\title{
Lipin-1 Contributes to IL-4 Mediated Macrophage Polarization
}

\author{
Sunitha Chandran ${ }^{1+}$, Robert M. Schilke ${ }^{1}$, Cassidy M. R. Blackburn' ${ }^{1}$ Aila Yurochko', \\ Rusella Mirza ${ }^{2}$, Rona S. Scott ${ }^{1}$, Brian N. Finck ${ }^{3}$ and Matthew D. Woolard ${ }^{1 *}$ \\ ${ }^{1}$ Department of Microbiology and Immunology, Louisiana State University Health Sciences Center, Shreveport, LA, \\ United States, ${ }^{2}$ Department of Pathology and Translational Pathobiology, Louisiana State University Health Sciences Center, \\ Shreveport, LA, United States, ${ }^{3}$ Division of Geriatrics and Nutritional Science, Washington University School of Medicine, \\ St. Louis, MO, United States
}

Macrophage responses contribute to a diverse array of pathologies ranging from infectious disease to sterile inflammation. Polarization of macrophages determines their cellular function within biological processes. Lipin-1 is a phosphatidic acid phosphatase in which its enzymatic activity contributes to macrophage pro-inflammatory responses. Lipin-1 also possesses transcriptional co-regulator activity and whether this activity is required for macrophage polarization is unknown. Using mice that lack only lipin1 enzymatic activity or both enzymatic and transcriptional coregulator activities from myeloid cells, we investigated the contribution of lipin-1 transcriptional co-regulator function toward macrophage wound healing polarization. Macrophages lacking both lipin-1 activities did not elicit IL-4 mediated gene expression to levels seen in either wildtype or lipin-1 enzymatically deficient macrophages. Furthermore, mice lacking myeloidassociated lipin-1 have impaired full thickness excisional wound healing compared to wild-type mice or mice only lacking lipin-1 enzymatic activity from myeloid cell. Our study provides evidence that lipin-1 transcriptional co-regulatory activity contributes to macrophage polarization and influences wound healing in vivo.

Keywords: lipin-1, macrophage, polarization, wound healing, transcriptional coregulator

\section{INTRODUCTION}

Macrophages are innate immune cells that mediate tissue homeostasis by polarizing into unique phenotypes that range from pro-inflammatory to wound healing. Macrophage cellular responses restore normal tissue function. Defects in macrophage polarization can influence numerous disease pathologies including infectious disease, atherosclerosis, tumor growth, and impaired wound closure. Activation of macrophages via pattern recognition receptors (i.e., Toll like receptors) or through pro-inflammatory cytokine receptors (i.e., IFN- $\gamma$ or TNF- $\alpha$ receptor) lead to proinflammatory activities (1). Conversely, IL-4, IL-10, IL-13, or TGF- $\beta$ stimulation of macrophages promotes wound healing activities. The binding of these cytokines to their respective receptors leads to the activation and inhibition of numerous transcriptions factors that promote polarization of macrophages to a wound healing state. Most critical to wound healing polarization is the peroxisome proliferator-activated receptors (PPAR) family of transcription factors (2). PPAR activation via ligand binding and association with co-activators leads to both trans-repressive and transactivating activity (3). In macrophages, PPARs can transrepress NF- $\kappa$ B and STAT1 at the promoters of pro-inflammatory cytokines such as TNF- $\alpha$ (4). PPARs also promote the expression of genes associated with both lipid catabolism (2) and macrophage wound-healing activity (5). 
Lipin-1 belongs to the evolutionarily conserved threemember lipin family (lipin-1, -2, and -3) in mammals. Lipins enzymatically convert phosphatidate into diacylglycerol via dephosphorylation. Among lipin family proteins, lipin-1 exhibits the highest phosphatidate-specific phosphohydrolase activity (6). We and others have shown that expression of a hypomorphic lipin-1 protein that lacks enzymatic activity attenuates proinflammatory macrophage responses by regulating glycerolipid synthesis (7-9). Lipin-1 enzymatic activity within macrophages contributes to disease pathogenesis of atherosclerosis, colitis, colon cancer, and LPS-induced inflammation [reviewed in (10)]. The overarching mechanism is likely due to lipin-1mediated diacylglycerol production leading to protein kinase $\mathrm{C}$ and AP-1 transcription factor activation driving proinflammatory macrophage activities (7-9). In addition to acting as a lipid phosphatase, lipin-1 also independently acts as a transcriptional co-regulator by interacting with various DNA-bound transcription factors. It is unknown if lipin-1 transcriptional co-regulator activity is involved in regulating wound healing activity in macrophages. However, lipin-1 augments PPAR activity to promote adipogenesis in adipocytes and promotes beta-oxidation while suppressing very low-density lipoprotein production in hepatocytes (11-15). Lipin-1 also represses the activity of SREBP1, SREBP2, and NFAT4c by inhibiting the binding of these transcription factors to their respective promoters in hepatocytes $(16,17)$. SREBP1, SREBP2, and NFAT4c have been identified to contribute to promotion of macrophage pro-inflammatory responses and inhibition of wound healing macrophage polarization (18-20). These studies suggest to us that in macrophages the potential of lipin1 transcriptional co-regulatory activity promoting PPARs and inhibiting SREBPs and NFAT4c might be important for the polarization of macrophages to a wound healing state. Our data provides evidence that lipin-1 transcriptional co-regulator activity contributes to IL-4 mediated macrophage wound healing function.

\section{MATERIALS AND METHODS}

\section{Animals}

All animal studies were approved by the LSU Health Sciences Center-Shreveport institutional animal care and use committee. All animals were cared for according to the National Institute of Health guidelines for the care and use of laboratory animals. After wounding, all mice were housed in individual filter-topped sterile cages, provided with sterile water and food ad libitum.

All animals used in this study were 8 to 10 -week-old mice. Mice lacking lipin-1 enzymatic activity from myeloid cells (lipin$\left.1^{\mathrm{mEnzy}} \mathrm{KO}\right)$ were generated as previously reported (9). Briefly, mice with exons 3 and 4 of the Lpin1 gene flanked by LoxP sites (genetic background: C57BL/6J and SV129; generously provided by Brian Finck and Roman Chrast) were crossed with C57BL/6J LysM-Cre transgenic mice purchased from Jackson Laboratory (Bar Harbor, ME, United States). Exon 3 encodes the translational start site of lipin-1; however, deletion of this exon led to enforcement of an alternative start site causing expression of a truncated lipin-1 protein lacking 115 amino acids (21). The truncated protein lacks phosphatidic acid phosphohydrolase activity but retains cotranscriptional regulatory function. Mice fully lacking lipin-1 from myeloid cells (lipin- $1^{\mathrm{m}} \mathrm{KO}$ ) were generated by crossing mice with exon 7 of the Lpin 1 gene flanked by LoxP sites [genetic background: C57BL/6J and SV129; generously provided by Brian Finck (22)] with C57BL/6J LysM-Cre transgenic mice purchased from Jackson Laboratory (Bar Harbor, ME). Deletion of exon 7 leads to frameshift, premature stop codon insertion, and a complete loss of lipin1 protein (22). Age matched lipin- $1^{\text {flox/flox }}$ littermate mice were used as controls.

\section{Excisional Wound Healing Model}

Mice were anesthetized by 3\% isoflurane (NDC, 14043-704-06) and clippers were used to remove hair from the dorsum. Exposed skin was disinfected with chlorohexidine swabs. Dorsal skin was folded, raised cranially, and mice were laterally positioned. Symmetric full thickness wounds were created using a sterile $5 \mathrm{~mm}$ biopsy punch (Integra) (23). Gross images were taken and percentage of wound closure was assessed using a digital caliper at $0,2,5,7,9,12$, and 14-days post-wounding and expressed as [(area of original wound - area of current wound)/area of original wound]x100. After initial wounding, analgesic cream was applied to wounds (Aspercreme, Cattem, 0078940). Mice were routinely monitored for weight loss or any other type of distress until the end of the study.

\section{Generation of Bone Marrow-Derived Macrophages}

Bone marrow-derived macrophages (BMDMs) were generated from lipin- $1^{\mathrm{mEnzy}} \mathrm{KO}$, lipin- $1^{\mathrm{m}} \mathrm{KO}$ and littermate control mice as previously described (24). Briefly, femurs were excised under sterile conditions and flushed with Dulbecco's modified Eagle's Knock out medium (DMEM; Gibco, 10829) supplemented with $10 \%$ fetal bovine serum (Atlanta biologicals, S11150), 2 mM L-glutamax (Gibco -35050-061), $100 \mathrm{U} / \mathrm{ml}$ penicillinstreptomycin (Cell Gro, 30-604-CI), $1 \mathrm{mM}$ sodium pyruvate (Cell gro, 25-060-CI), and $0.2 \%$ sodium bicarbonate (Quality biological, 118-085-721). Red blood cells were lysed using ammonium chloride-potassium carbonate $\left(0.15 \mathrm{M} \mathrm{NH} \mathrm{NH}_{4} \mathrm{Cl}\right.$, $10 \mathrm{mM} \mathrm{KHCO}_{3}, 0.1 \mathrm{mM} \mathrm{NA}_{2}$ EDTA, adjusted to $\mathrm{pH} 7.2$ and filter sterilized in $0.22 \mu \mathrm{m}$ filter) lysis (ACK) followed by PBS wash. Isolated cells were incubated in sterile petri dishes for 7 to 10 days in BMDM differentiation medium - DMEM KO (Gibco10829) supplemented with $30 \%$ L-cell conditioned medium, $20 \%$ fetal bovine serum [Atlanta biologicals, S11150) $2 \mathrm{mM}$ L-glutamax (Gibco -35050-061), $100 \mathrm{U} / \mathrm{ml}$ penicillin-streptomycin (Cell Gro, 30-604-CI), 1mM sodium pyruvate (Cell Gro, 25-060-CI)], and $0.2 \%$ sodium bicarbonate (Quality biological, 118-085-721) at $37^{\circ} \mathrm{C}$ and $5 \% \mathrm{CO}_{2}$. Once cells were $80 \%$ confluent, they were collected using $11 \mathrm{mM}$ EDTA, pH 7.6 treatment. $10^{6}$ cells were seeded for RNA extraction and $5 \times 10^{5}$ cells for protein isolation and flow cytometry analysis. After $4 \mathrm{~h}$ of seeding, cells were treated with 0 or $20 \mathrm{ng} / \mathrm{ml}$ IL-4 (R\&D Biosystems, 404-ML-050) for various times. 


\section{Flow Cytometry}

\section{Interleukin-4 Receptor Staining}

Bone marrow-derived macrophages were incubated with CD16/CD32 (e-Bioscience, 14-0161-86) for $20 \mathrm{~min}$. BMDMs were then incubated with PECy7 conjugated anti-CD11b (e-Bioscience, 25-0112-81, clone M1/70), and PE conjugated anti-IL-4R (Biolegend, 144803) for $30 \mathrm{~min}$ in the dark. Cells were then fixed with $4 \%$ formaldehyde and analyzed using BD LSRII (San Jose, CA, United States).

\section{Immune Composition Staining}

Spleens were homogenized in FACS wash buffer (1\% bovine serum albumin, $1 \mathrm{mM}$ EDTA, and $0.1 \%$ sodium azide in phosphate buffered saline) followed by centrifugation at $300 \times g$ for $5 \mathrm{~min}$. The supernatant was decanted and splenocytes were dislodged in $3 \mathrm{ml}$ of ACK lysis buffer. Splenocytes were incubated on ice for $5 \mathrm{~min}$. Splenocytes were washed in FACS wash buffer then centrifuged. The pellet was re-suspended in FACS wash buffer and strained with a $40 \mu \mathrm{m}$ cell strainer (Falcon, 352340), and counted. Splenocytes were adjusted to $1 \times 10^{6}$ cells $/ \mathrm{mL}$ in RPMI. Blood was collected in EDTA coated tubes. $100 \mu \mathrm{l}$ of blood was lysed in $3 \mathrm{mls}$ of ACK lysis buffer and then washed with FACS wash buffer. The entire sample of blood cells were stained. Splenocytes and blood cells were incubated with anti-CD16/CD32 (e-Bioscience, 14-0161-86) for $20 \mathrm{~min}$. After blocking, cells were stained with a cocktail of antibodies: AF700 conjugated anti-CD45.2 (Biolegend,109821,clone104), BV605 conjugated anti-CD3 (Biolegend,100237,clone17A2), BV786 conjugated anti-CD11c (BD Biosciences,563735,cloneHL3), PECy7 conjugated anti-CD11b (eBioscience, 25-0112-81, clone M1/70), PEe610 conjugated anti-CD19 (eBioscience,610193-80,clone eBio1D3), FITC conjugated anti-Ly6G (BD Biosciences,551460,clone1A8), PE conjugated anti-Ly6C (eBioscience,12-5932-80,clon eHK1.4) and APC-Cy7 conjugated anti-CD115 (Biolegend,135532,cloneAFS 98). Appropriate F Minus One Controls were used to correct background and exclude spectral overlap staining. Compensation control (Comp Bead, Invitrogen, 01-2222-42) were used. Flow cytometry analysis was performed using BD LSRII (San Jose, CA). Data analysis was done using FCS express (Denovo Software) and NovoExpress (AceaBio).

\section{Wound Staining}

Quantification of macrophage phenotypes within the wound was performed as previously described (25). Briefly dorsal skin was carefully removed from the euthanized mice and placed onto filter paper. $10 \mathrm{~mm} \times 10 \mathrm{~mm}$ tissue specimen including the wounded area and adjacent tissue was made. Subcutaneous fat and muscle were removed from the tissue and wound was minced into 4-5 smaller pieces. Tissue was further digested in Dispase II enzyme cocktail ( $2 \mathrm{mg} / \mathrm{mL}$, Thermo Fisher Scientific 17105-041 and $0.1-\mathrm{mg} / \mathrm{mL}$ DNase I Roche, cat. \#10104159001) in a volume of $700 \mu$ L DMEM (Gibco10829) media and incubated in a shaker at $1,400 \mathrm{rpm}, 37^{\circ} \mathrm{C}$ for $2 \mathrm{~h}$. After incubation, undigested debris was removed by filtering the sample through $70 \mu \mathrm{m}$ strainer. Add $500 \mu \mathrm{L}$ of cold FACS wash buffer to the side of strainer to wash off the remaining cells into the collection tube. Centrifuge at $4^{\circ} \mathrm{C}$ for $5 \mathrm{~min}$ at $400 \times \mathrm{g}$. Remove the supernatant and resuspend the cell pellet in $200 \mu \mathrm{L}$ cold FACS buffer. $0.5 \times 10^{6}$ cells were then stained first for dead cells using Invitrogen aqua live/dead stain (Thermo Fisher Scientific L34965). After live/dead staining, cells were stained with anti-CD16/CD32 (e-Bioscience, 14-0161-86) for $20 \mathrm{~min}$. After blocking, cells were stained with a cocktail of antibodies: AF700 conjugated anti-CD45.2 (Biolegend,109821,clone104), PECy7 conjugated anti-CD11b (eBioscience, 25-0112-81, clone M1/70), FITC conjugated antiLy6G (BD Biosciences,551460,clone1A8), PE-Cy5 conjugated anti-F4/80 (Invitrogen, 15-4801-80, clone BM8), and AF647 conjugated anti-CD206 (Biolegend, 141711, clone C068C2). Appropriate F Minus One Controls were used to correct background and exclude spectral overlap staining. Compensation control (Comp Bead, Invitrogen, 01-2222-42) were used. Flow cytometry analysis was performed using Novocyte Quanteon (Aceo Bio). Data analysis was done using FCS express (Denovo Software) and NovoExpress (AceaBio).

\section{Western Blot}

Cells were lysed in $1 \times$ NuPage LDS sample buffer [containing $100 \mathrm{mM}$ dithiothreitol (DTT; Life Technologies), $1 \times$ protease inhibitor cocktail (Thermo Fisher Scientific), $1 \times$ phosphatase inhibitor cocktail 2 (Sigma Aldrich), and $1 \times$ phosphatase inhibitor cocktail 3 (Sigma Aldrich)]. Protein concentration was determined by Peirce ${ }^{\mathrm{TM}} 660 \mathrm{~nm}$ Protein Assay (Thermo Fisher Scientific) and $20 \mu \mathrm{g}$ of each sample was separated using 4 to $12 \%$ polyacrylamide NuPAGE Novex gel (Invitrogen) run at $200 \mathrm{~V}$ for $55 \mathrm{~min}$. Semidry transfer (Novex, SD1000) was performed for $45 \mathrm{~min}$ at $20 \mathrm{~V}$ onto a polyvinylidene difluoride (Immobilon-FL) membrane (EMD Millipore). The membranes were further blocked for $1 \mathrm{~h}$ at room temperature using Li-Cor blocking buffer (Li-Cor Biosciences) and incubated overnight with primary antibodies for Lipin-1 (CST \#14906), P-STAT6 (CST \#56554), STAT6 (CST \#5397), and GAPDH (CST \#2118). Goat anti-rabbit HRP secondary antibody (Jackson \#111-035144) was added to the membranes and incubated for $2 \mathrm{~h}$ at room temperature. Membranes were washed three times with tris buffered saline with tween 20 and incubated in ImmunoCruz Western blotting luminol reagent (Santa Cruz, sc-2048) for $1 \mathrm{~min}$. Images were captured using an Amersham Imager 680 (GE Healthcare Bio-Sciences). Densitometry was performed using IQTL 8.1 (GE Healthcare Biosciences). Bands of interest were normalized to GAPDH.

\section{Quantitative Real Time PCR}

Bone marrow-derived macrophages were treated with IL-4 (R\&D Biosystems, 404-ML-050) for $4 \mathrm{~h}$ and mRNA was extracted from the cultured cells using RNeasy Mini Kit (Qiagen - 74106) as per manufacturer's instructions. cDNA template was generated using qScript cDNA SuperMix (Quantabio, 95048). qRT-PCR was performed in a Biorad iCycler with SsoAdvanced Universal SYBER Green SuperMix (Biorad, 172-5271). Primers (Table 1) were obtained from the Harvard primer bank database. Primer specificity was confirmed using primer BLAST and by verifying the presence of a single peak in melt curve analysis. Results were 
TABLE 1 | Primers used for Quantitative Real Time PCR.

\begin{tabular}{lll}
\hline Gapdh & AGTGGCAAAGTGGAGATT & GTGGAGTCATACTGGAACA \\
\hline Arg1 & TGTCCCTAATGACAGCTCCTT & GCATCCACCCAAATGACACAT \\
Socs2 & TGCGGATTGAGTACCAAGATGG & CTGTCCGTTATCCTTGCACA \\
Cc/17 & TACCATGAGGTCACTTCAGATGC & GCACTCTCGGCCTACATTGG \\
/10 & CCCATTCCTCGTCACGATCTC & TCAGACTGGTTGGGATAGGTा \\
Mannr & GATATGAAGCCATGTACTCC & GGCAGAGGTGCAGTCTGCAT \\
& TTACTGG & \\
Pparg & GGAAGACCACTCGCATTCCTT & GTAATCAGCAACCATTGGGTCA
\end{tabular}

expressed as fold change relative to IL- 4 treated WT cells by $2^{-\Delta \Delta \mathrm{Ct}}$ method after normalizing with GAPDH.

\section{Phagocytosis Assay}

Bone marrow-derived macrophages $\left(5 \times 10^{5}\right.$ cells $)$ were cultured on sterile coverslips in culture wells and treated with $20 \mathrm{ng} / \mathrm{ml}$ IL-4 for 24 h. Culture medium was then replaced with DMEM, containing pHrodo ${ }^{\mathrm{TM}}$ green Zymosan A BioParticles ${ }^{\circledR}$ (Thermo Fisher Scientific, P35365) such that each well receives $0.1 \mathrm{mg}$ zymosan particles. BMDMs were allowed to phagocytose for $1 \mathrm{~h}$ under dark incubation and then the assay was stopped by cold PBS wash. Cells seeded on coverslips were then fixed using $4 \%$ formaldehyde. Cells on cover slips were washed three times and then stained with DAPI slowfade (Invitrogen, S36938). Immunofluorescent images were taken using Olympus BX51 and evaluated using Image J (1.50a) analysis software. Phagocytic efficiency for each image was calculated by dividing the total number of fluorescent beads by the total number of nuclei in the fluorescent image, thus giving average number of beads per cell. Experiment was performed 3 times with 4 random images per group $(n=12)$.

\section{Histology}

Wound area was carefully excised at 2, 5, and 14 days after wounding and fixed in $10 \%$ neutral buffered formalin followed by paraffin embedding. $5 \mu \mathrm{m}$ thick sections were cut from formalin-fixed paraffin-embedded tissue blocks. Sections were rehydrated, followed by hematoxylin-eosin (H\&E) staining and dehydration. Stained sections were then imaged using Olympus BX51. $4 \times$ images were compared between each group to assess wound healing. Morphological score of inflammation: Evaluation of cellular infiltrate (polymorphonuclear and mononuclear cells) was done on $H \& E$ stained sections using the $10 \mathrm{x}$ objectives. The cells were counted at the wound bed and scored as 0 , 1,2 , and 3 (absence of inflammation, Discrete-presence of few inflammatory cells, Moderate-many inflammatory cells and Severe-exaggerated inflammatory cellularity, respectively) for whole skin. The cellularity of the overlying crust or scab was excluded from the score. The scab was made of fibrin and polymorphonuclear cells. The scab was interpreted as either thin (scored as 1) or thick (Scored as 2) based on their morphological appearance on $\mathrm{H} \& \mathrm{E}$ sections. Scoring was performed in a blinded fashion.

\section{Cytometric Bead Array}

Serum cytokine concentration was measured using Biolegend LEGENDplex (Biolegend Mouse inflammation Panel \#740446). The assay was performed according to the manufacturer's instructions, and all samples were run in duplicate. Data was analyzed using the LEGENDplex Data Analysis Software.

\section{Statistical Analysis}

GraphPad Prism 5.0 (La Jolla, CA, United States) was used for statistical analyses. All data was tested for normalcy using the Shapiro Wilks Normalcy test. If data was normally distributed student $T$ Test analysis was used for comparison between two data sets. If data was not normally distributed a MannWhitney test was performed. All other statistical significance was determined using a one-way ANOVA analysis of variance with a Dunnett's post-test. All in vivo experiments were performed a minimum of two times and all in vitro experiments were performed a minimum of three times. Figure legends provide specific details for each data set.

\section{RESULTS}

\section{Lipin-1 Contributes to IL-4 Elicited Gene Expression}

Pro-inflammatory response in macrophages is influenced by lipin-1, but if lipin-1 contributes to wound healing responses by macrophages is unknown. We have previously generated lipin- $1^{\text {mEnzy }} \mathrm{KO}$ mice that express a truncated lipin-1 protein lacking lipin-1 enzymatic activity but retain transcriptional co-regulatory function in myeloid cells (9). Here, we generated lipin- ${ }^{\mathrm{m}} \mathrm{KO}$ mice that lack the entire lipin-1 protein in myeloid cells. Comparing results between lipin-1 ${ }^{\mathrm{mEnzy}} \mathrm{KO}$ mice and lipin- $1^{\mathrm{m}} \mathrm{KO}$ mice allows us to determine the contribution of lipin-1 enzymatic activity and infer the contribution of lipin-1 transcriptional coregulator activity on macrophage function. We have previously demonstrated the ability to generate BMDMs from lipin- $1^{\text {mEnzy }} \mathrm{KO}$ mice and confirmed their phenotype (9). We confirmed that the loss of full lipin-1 did not inhibit BMDM generation based on CD11b staining by flow-cytometry (Figure 1A). Western Blot analysis of proteins collected from cultured BMDMs demonstrated roughly an $85 \%$ reduction of lipin-1 protein in lipin- $1^{\mathrm{m}} \mathrm{KO}$ BMDMs, residual lipin-1 protein is due to ineffective Cre excision of lipin-1 (Figure 1B) (26). Having generated macrophages lacking lipin-1, we investigated the contribution of lipin-1 to IL-4 mediated gene expression. BMDMs from lipin- $1^{\mathrm{mEnzy}} \mathrm{KO}$, lipin $-1^{\mathrm{m}} \mathrm{KO}$, and appropriate littermate controls were stimulated with $20 \mathrm{ng} / \mathrm{ml}$ of IL-4 for $4 \mathrm{~h}$. mRNA was isolated and analyzed for the expression of several canonical wound-healing associated genes: Arg1, Socs2, Ccl17, Mannr, Il10, and Pparg (27). We included littermate controls for both strains; however, no differences were noted between lipin- $1^{\mathrm{m}} \mathrm{KO}$ and lipin- $1^{\mathrm{mEnzy}} \mathrm{KO}$ littermate controls, therefore littermate controls were grouped together as wild type. Expression of several wound healing associated genes in wildtype, lipin- ${ }^{\mathrm{mEnzy}} \mathrm{KO}$ and lipin- ${ }^{\mathrm{m}} \mathrm{KO}$ BMDMs (Figure 1C) were comparable. However, IL-4 elicited gene expression 
A

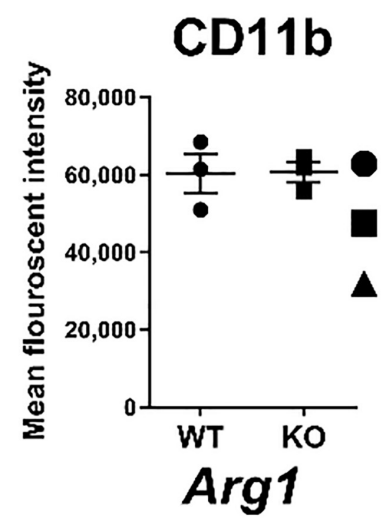

C
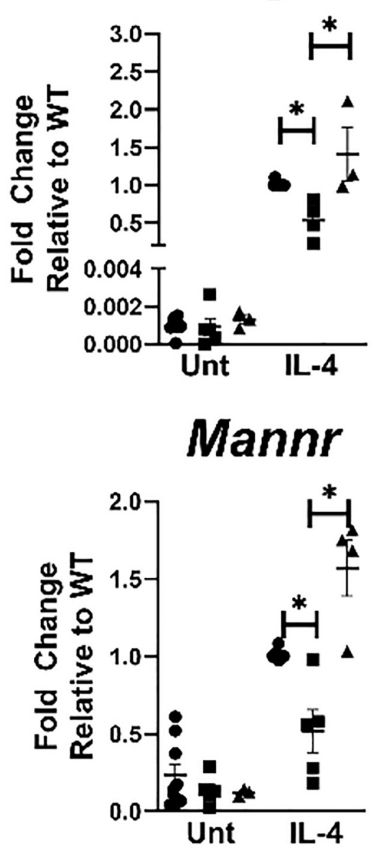

B
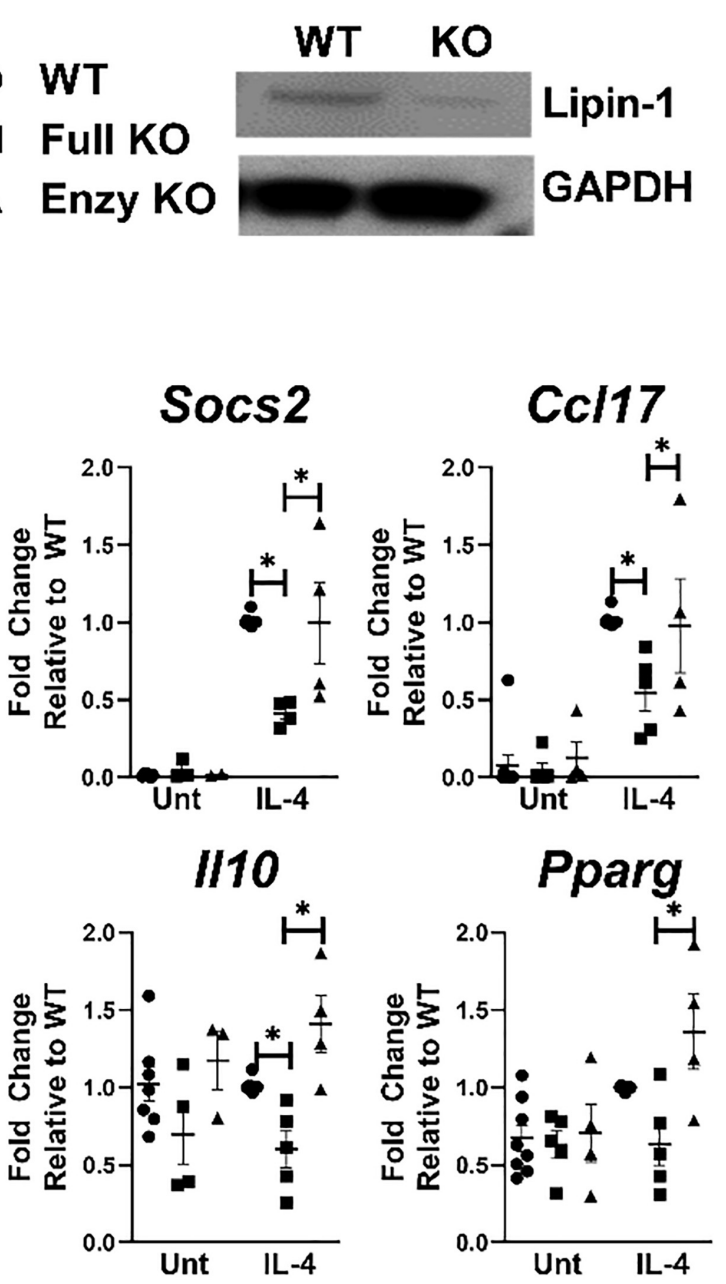

FIGURE 1 | Lipin-1 promotes IL-4 mediated gene expression. (A) Flow cytometry was used to quantify CD 11b surface expression of BMDMs from lipin-1 ${ }^{\mathrm{m}} \mathrm{KO}$ and littermate controls. Each dot represents an independent experiment. (B) Lipin-1 was quantified by Western blot analysis, representative image of three independent experiments shown. (C) BMDMs generated from lipin- $1^{\mathrm{m}} \mathrm{KO}$, lipin-1 ${ }^{\mathrm{mEnzy}} \mathrm{KO}$ and their respective littermate control mice. BMDMs were stimulated with 20 ng/ml IL-4 for $4 \mathrm{~h}$. mRNA was isolated and wound healing associated genes were quantified by qRT-PCR. No difference was noted between littermate controls as such they were combined in WT. Each dot represented an individual experiment. Experiments were performed a minimum of three times. All data were normal except for WT IL-4 treated gene expression. Mann Whitney test was used for comparing WT and lipin- $1^{\mathrm{m}} \mathrm{KO}$; unpaired $T$ test used for comparing lipin- ${ }^{\mathrm{m}} \mathrm{KO}$ and lipin-1 $\mathrm{mEnzyKO}$ Data presented is mean $\pm \mathrm{SEM},{ }^{*} p<0.05$.

was significantly lower in lipin $-1^{\mathrm{m}} \mathrm{KO}$ BMDMs compared to either wild type or lipin-1 ${ }^{\text {mEnzy }} \mathrm{KO}$ BMDMs. These results demonstrate that lipin-1 enzymatic activity is dispensable for IL-4 mediated gene expression and suggests that lipin-1 transcriptional co-regulatory activity influences IL-4-mediated gene expression in macrophages.

\section{Lipin-1 Does Not Influence Surface Expression of IL-4 Receptor or STAT6 Phosphorylation}

Lipid membrane composition can influence the localization of receptors and/or signaling through those receptors (28). Lipin-1 is a regulator of glycerol lipid synthesis and the loss of lipin1 may cause loss of either IL-4 receptor surface expression or signaling through the IL- 4 receptor, thus resulting in impaired responses to IL-4. Flow cytometric evaluation of the surface expression of IL-4 receptor showed no difference between wild type and lipin- $1^{\mathrm{m}} \mathrm{KO}$ BMDM (Figure 2A). Ligand binding of the IL- 4 receptor- $\alpha$ (IL $4 \mathrm{R} \alpha)$ triggers tyrosine phosphorylation at the cytoplasmic tail to facilitate recruitment and subsequent tyrosine phosphorylation of STAT6 by JAK1/JAK3 pathway (29). Wildtype and lipin- $1^{\mathrm{m}} \mathrm{KO}$ BMDMs were stimulated with IL-4 for 30 min (Figure 2B), 1 and $4 \mathrm{~h}$ (Supplementary Figure 1) and protein was collected. Total STAT6 and phosphorylated STAT6 was measured by Western blot analysis. Similar levels of STAT6 
A

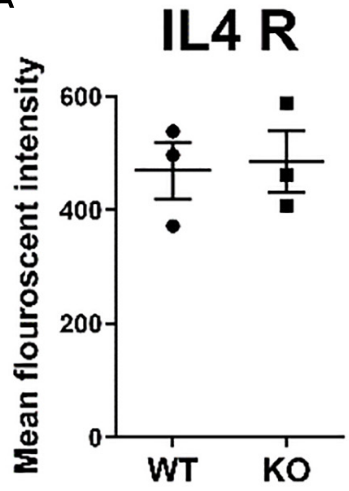

B

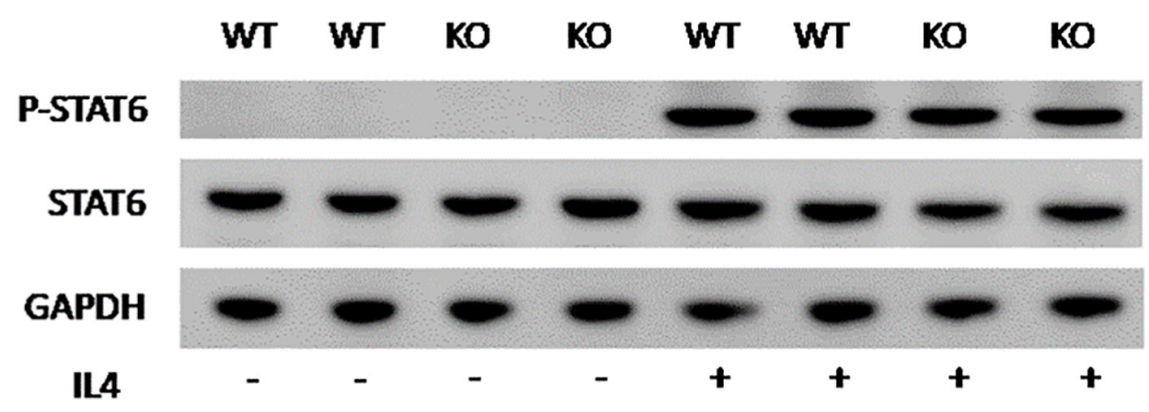

FIGURE 2 | Lipin-1 does not regulate IL-4 mediated STAT6 phosphorylation. (A) Flow cytometry was used to quantify surface expression of IL-4R in unstimulated BMDMs from lipin- $1^{\mathrm{m}} \mathrm{KO}$ and litter mate controls (mean $\pm \mathrm{SEM} n>3$ from 3 independent experiments). (B) BMDMs from lipin- $1^{\mathrm{m}} \mathrm{KO}$ and litter mate controls were stimulated with $20 \mathrm{ng} / \mathrm{ml} \mathrm{IL-4}$ for $30 \mathrm{~min}$. Protein was isolated and p-STAT6, STAT6 was quantified by Western blot analysis. A representative blot from three independent experiments is shown.

phosphorylation was observed between wild type and lipin$1^{\mathrm{m}} \mathrm{KO}$ BMDMs (Figure $2 \mathbf{B}$ ). These results show that defective IL-4 elicited gene expression in lipin- $1^{\mathrm{m}} \mathrm{KO}$ BMDMs was likely not due to a failure in IL-4 binding to the IL- 4 receptor and subsequent STAT6 phosphorylation.

\section{Lipin-1 Is Required for Phagocytosis}

The reduction in wound healing-associated genes in response to IL-4 suggests that lipin-1 contributes to macrophage wound healing function. Macrophages with a wound healing phenotype can have increased phagocytic capabilities (30). We investigated the ability of BMDMs to phagocytize zymosan beads. We mock treated or IL- 4 treated BMDMs from lipin- $1^{\mathrm{m}} \mathrm{KO}$ or litter mate controls for $24 \mathrm{~h}$. We then fed the macrophages $\mathrm{pHrodo}^{\mathrm{TM}}$ green Zymosan A BioParticles for $1 \mathrm{~h}$. These particles do not fluoresce at $7.6 \mathrm{pH}$ but do fluoresce at acidic $\mathrm{pH}$, making it easier to identify internalized particles. We then imaged using fluorescent microscopy and quantified average number of particles per cell. IL-4 stimulated lipin- ${ }^{\mathrm{m}} \mathrm{KO}$ BMDMs had fewer particles per cell than wild type BMDMs (Figure 3). These results further implicate the importance of lipin-1 in macrophage function.

\section{Myeloid-Associated Lipin-1 Contributes to Wound Healing in vivo}

Our in vitro studies suggest that lipin-1 contributes to IL-4 mediated macrophage polarization. We next wanted to determine if these in vitro differences contribute to in vivo processes as well. Polarization of macrophages to a wound healing phenotype is required for proper wound closure in a full excision wounding model $(31,32)$. We decided to investigate if the loss of myeloidassociated lipin-1 would alter wound closure. We performed full excision wounding on lipin- $1^{\mathrm{m}} \mathrm{KO}$, lipin- $1^{\mathrm{mEnzy}} \mathrm{KO}$ and their respective littermate controls. We monitored wound closure at early (day 2 and day 5), middle (day 7 and day 9), and late (day 12 and day 14) stages of wound healing. Lipin- $1^{\mathrm{m}} \mathrm{KO}$ mice had an initial delay in wound healing (days 2, 5, and 7) as compared to litter mate controls (Figures 4A,B). 9 days after wounding, wounds were of comparable size between lipin- $1^{\mathrm{m}} \mathrm{KO}$ mice and litter mate controls. In contrast, lipin- $1^{\text {mEnzy }} \mathrm{KO}$ did not differ from littermate controls in wound healing at any stage of healing (Figures 4C,D). These results demonstrate that lipin-1 enzymatic activity in myeloid cells is dispensable for full excision wound closure and suggests that lipin-1 transcriptional co-regulatory activity in myeloid cells influences full excision wound closure.

\section{Lipin-1 Deletion Does Not Alter Myeloid Immune Composition}

Loss of lipin-1 could potentially influence development of myeloid cells or myeloid mediated systemic responses. We examined myeloid population in the spleen and blood to see if there were any alterations that may explain the delay in wound healing. We isolated the spleen and blood at days 2, 5, and 14 post-wounding. Cells were isolated and stained with a panel of antibodies to quantify macrophages, monocytes, PMNs, and Ly6C $\mathrm{C}^{+}$monocytes. We included Ly6C staining as Ly6C $\mathrm{C}^{\mathrm{hi}}$ and Ly6 $\mathrm{C}^{\text {lo }}$ can both contribute to wound healing (33). We observed no significant difference between lipin- $1^{\mathrm{m}} \mathrm{KO}$ and litter mate control mice in any myeloid cell population analyzed in the blood or spleen (Figures 5A,B). In addition to monitoring cellular responses, we also examined mice serum cytokine concentration, 2 days post-wounding. We chose day 2 as this day correlated with the biggest difference in wound size. No differences were noted in serum cytokine responses between lipin- $1^{\mathrm{m}} \mathrm{KO}$ and littermate control mice (Figure 5C). These data suggest that myeloid associated lipin-1 activity that contributes to wound healing is likely mediated in the local environment rather than systemically.

\section{Loss of Lipin-1 Leads to Alteration in Wound Immune Composition}

Impaired healing was prominent in the early stage of wound healing. Hence, further histopathological evaluation (Figure 6A) was performed by $\mathrm{H} \& \mathrm{E}$ staining in isolated wounds from lipin- $1^{\mathrm{m}} \mathrm{KO}$ and littermate control mice at 2- and 5-days 


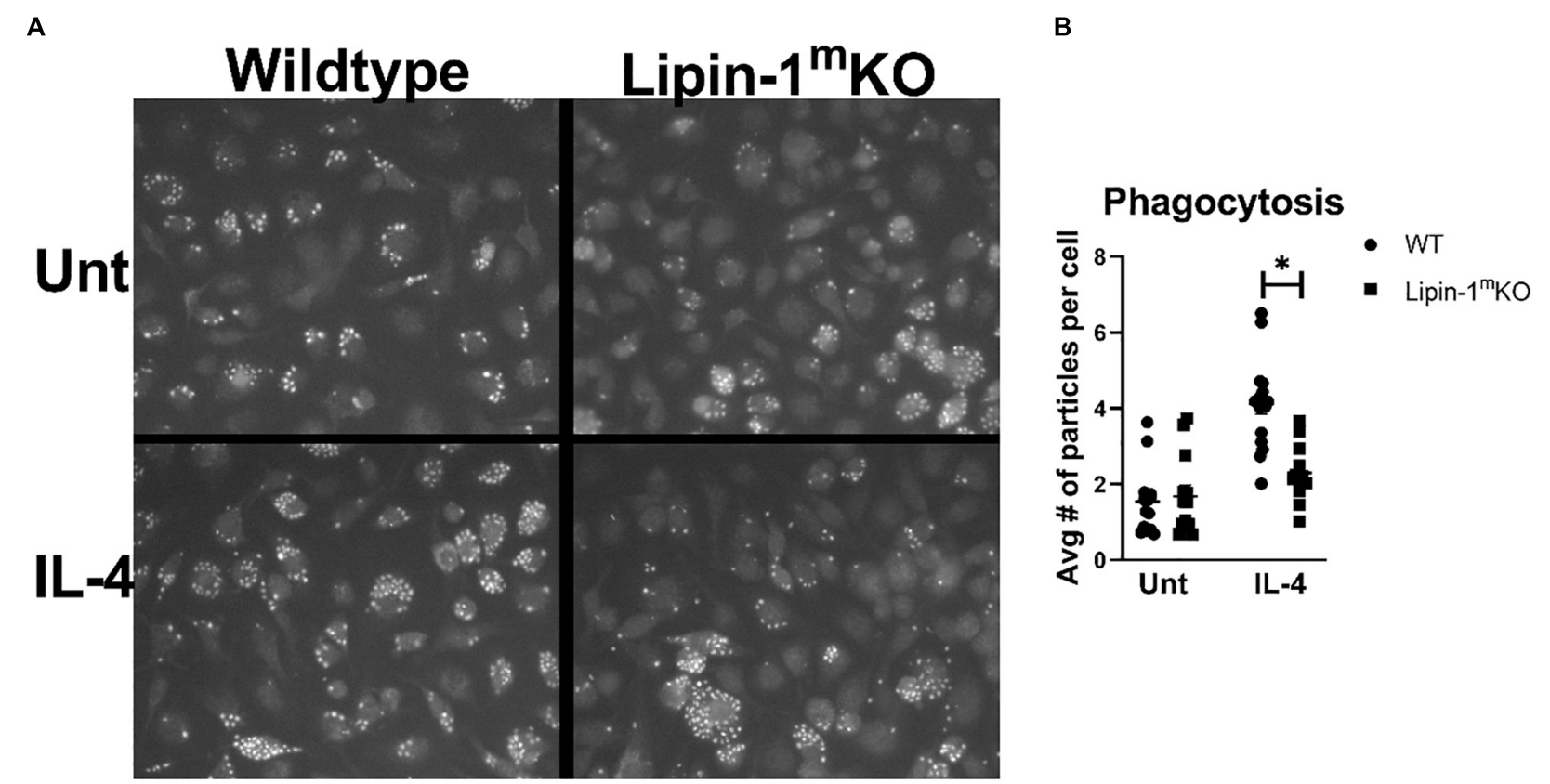

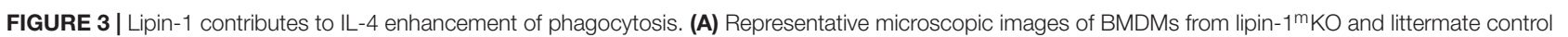
mice fed pHrodo-Green zymosan particles. (B) Quantification of number of beads (zymosan beads) divided by number of nuclei in a given image. Experiment was performed 3 times with 4 random image panels taken per group for a total of 12 images. Each dot represents analysis of a single image (mean \pm SEM $n=12$, $\left.{ }^{*} p<0.05\right)$.

A

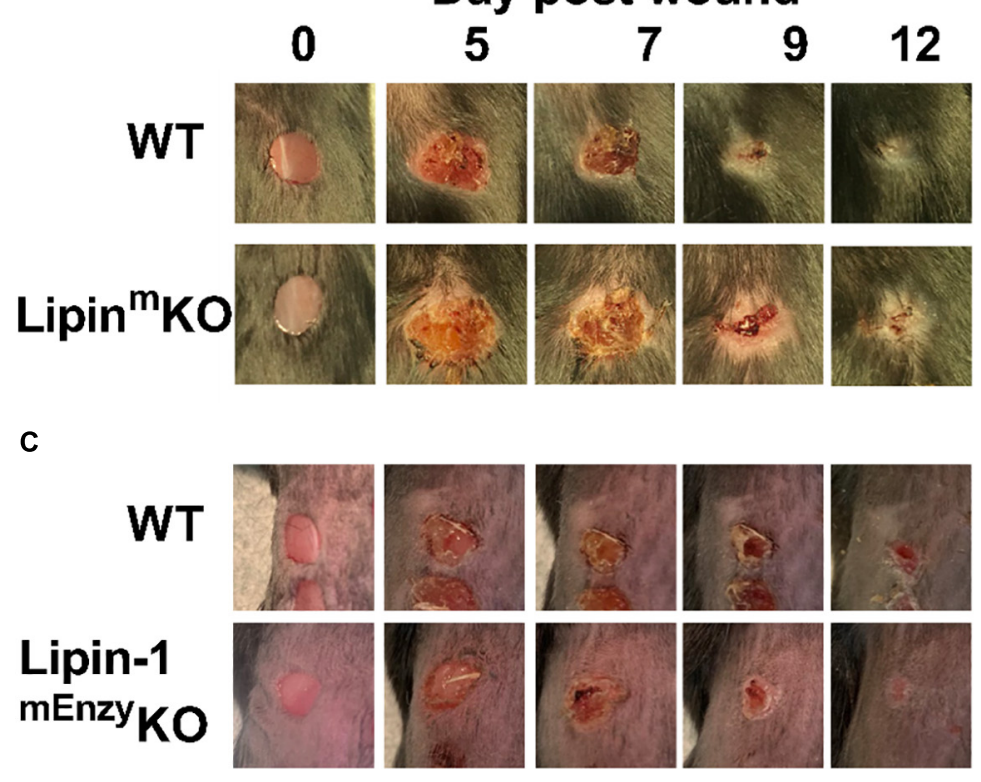

B

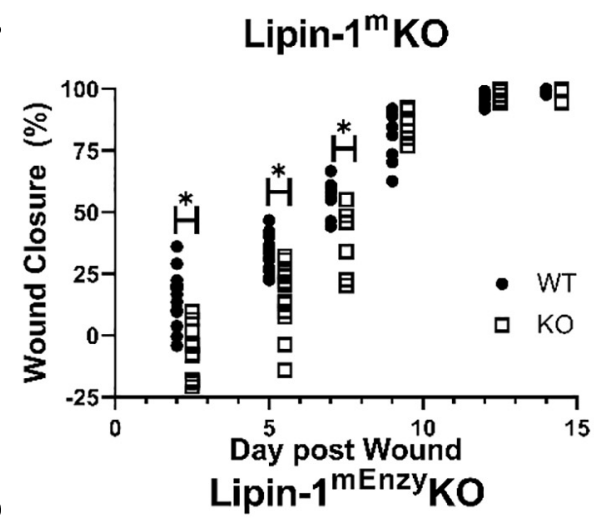

D

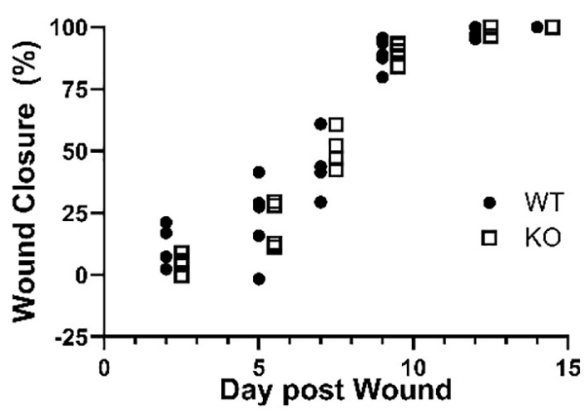

FIGURE 4 | Loss of full lipin-1 delays wound closure. (A,C) Representative image of gross lesions. (B,D) Percent wound closure as [(area of original wound - area of current wound)/area of original wound] $\times 100$. Wound measurements were made on days $0,2,5,7,9,12$, and 14 post-wounding. KO mice are shifted by a half day in graph in order to see differences (Experiment was performed a minimum of three times and each dot represents a single animal) ${ }^{\star} p<0.05$. Each symbol represents an individual mouse. 
A

Macrophages

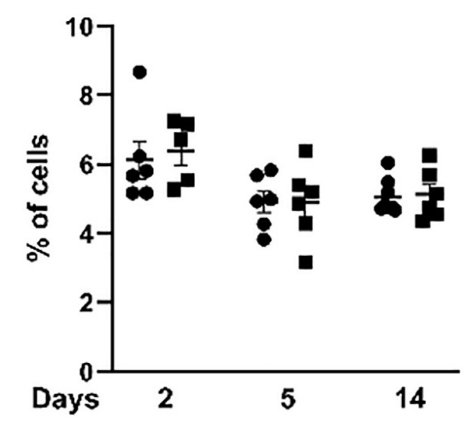

B

Monocytes

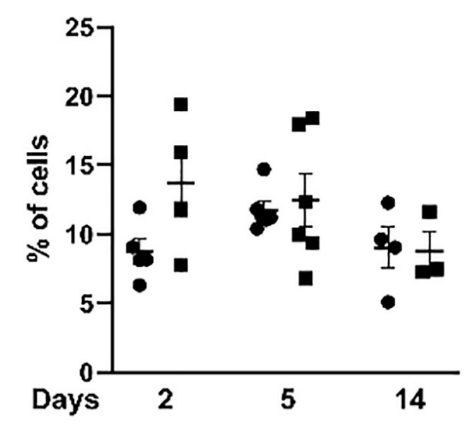

C

Cytokine responses

\section{Spleen}

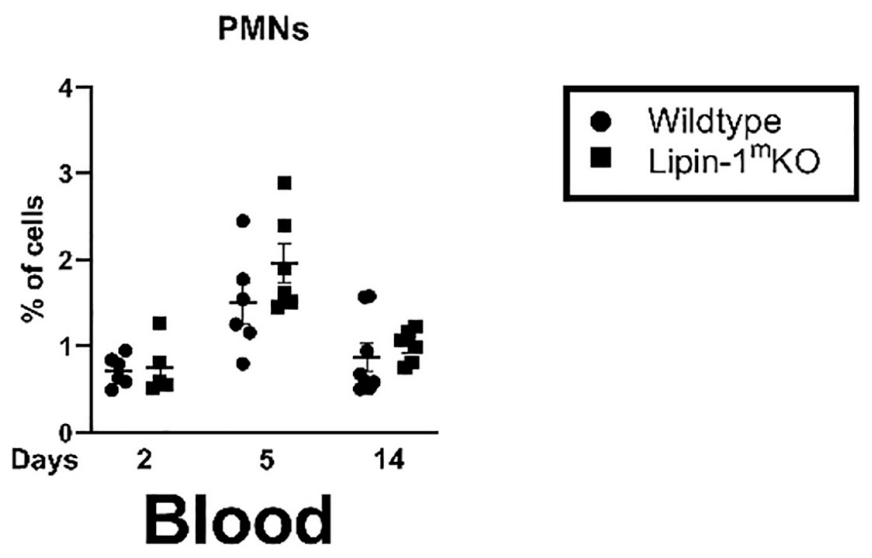

\section{PMNs}

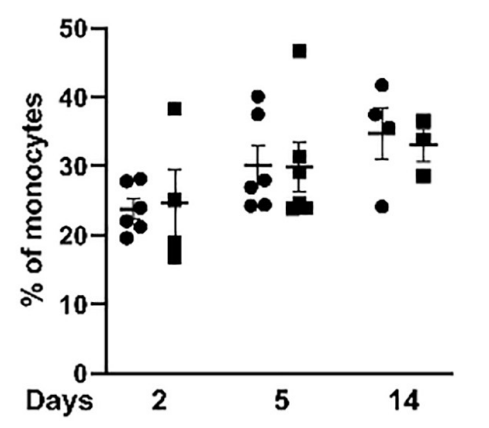

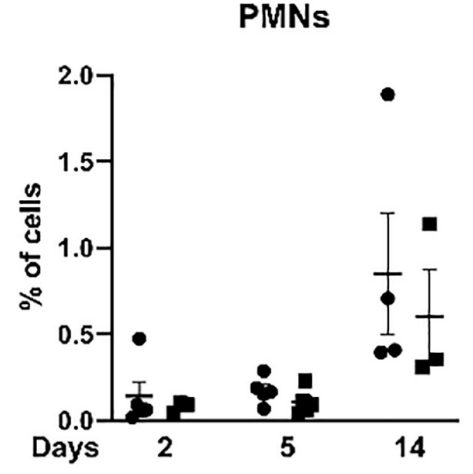

Cytokine responses
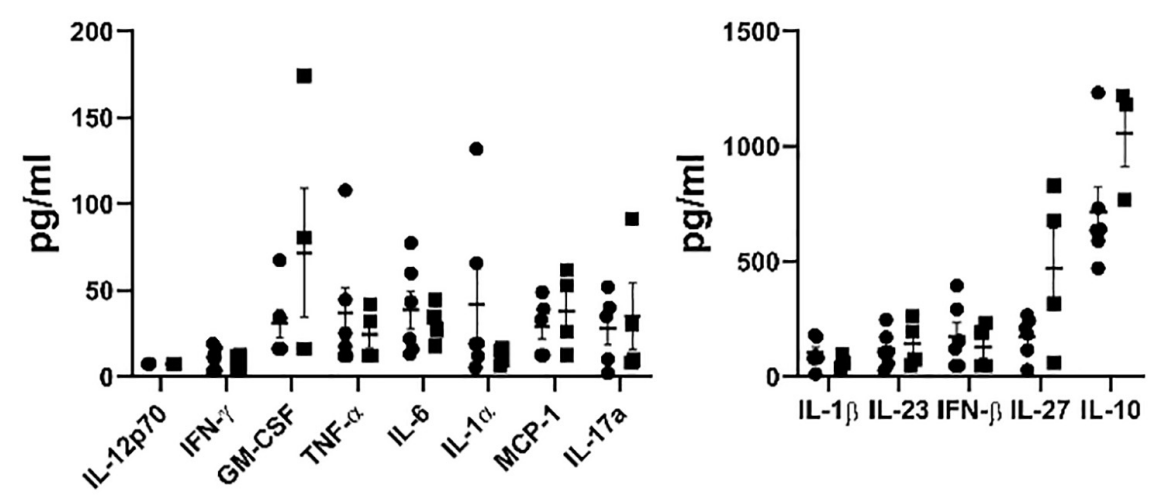

FIGURE 5 | Loss of lipin-1 does not alter systemic immune responses. (A) Splenocytes and (B) blood cells were stained with a panel of antibodies to quantify monocyte/macrophage and PMN populations. Myeloid populations were defined as CD45 ${ }^{+}, \mathrm{CD}^{-} \mathrm{CD}^{-} \mathrm{9}^{-} \mathrm{CD} 11 \mathrm{~b}^{+}$. PMNs were CD11b ${ }^{+} \mathrm{Ly}_{6 \mathrm{~g}}{ }^{+}$and monocytes were CD11 $b^{+}$Ly6G $^{-}$. Each dot represents an individual animal. Experiment was performed twice (mean \pm SEM). (C) Cytometric bead arrays to quantify cytokine concentrations in serum taken from mice 2 days after wounding Each dot represents an individual animal. Experiment was performed twice (mean \pm SEM).

post wounding. On day 2, slightly interrupted superficial layer with void spaces were seen at the wound site; scattered mononuclear cells and neutrophils were also observed within the superficial layer in control mice. In Lipin $-1^{\mathrm{m}} \mathrm{KO}$ mice, the superficial layer was poorly bridged with large void spaces with more inflammatory cells (Figure 6A). A very thick crest/scab was evident at the wound area which was highly infiltrated with mononuclear cells and neutrophils indicative of hyper inflammatory phase in Lipin- $1^{\mathrm{m}} \mathrm{KO}$ mice. On day 5 epidermal tongue (depicted by yellow arrow heads) extended toward the center of the wound, indicative of wound bridging and healing in control mice. But, in lipin $-1^{\mathrm{m}} \mathrm{KO}$ mice, the crest region was 


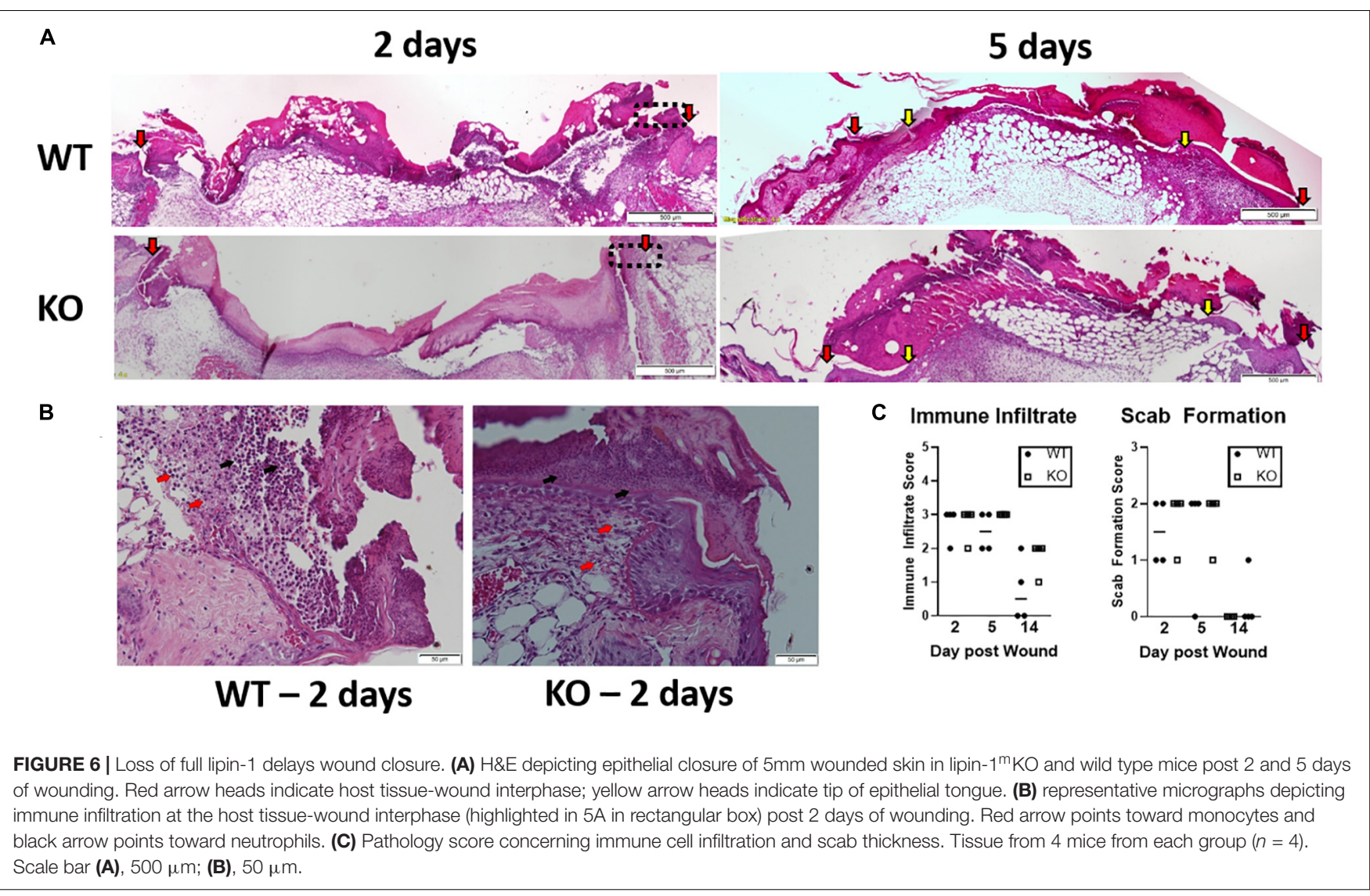

still thick with large number of immune infiltrates and they lacked a definitive epidermal closure and organization, suggestive of impaired healing. Wound closure (interphase between host tissue and wound depicted by red arrow heads) was also improved in the control mice. Scoring of the stained sections (03 inflammatory infiltrate and $0-2$ crust thickness) by a blinded pathologist showed no significant difference in inflammatory recruitment in lipin- $1{ }^{\mathrm{m}} \mathrm{KO}$ mice (Figures 6B,C).

We wanted to further investigate whether loss of lipin-1 influence inflammation within the wound during early stage of healing and alter macrophage profiles. To analyze immune cells within the wound we isolated $1 \mathrm{~cm}^{2}$ skin including wound and surrounding tissue. Immune cells were isolated from digested skin and then phenotypically characterized by flow cytometry. As we were looking at early time frame within the immune response to wound healing, we concentrated on innate immune cells by quantifying the number of leukocytes (CD45 + cells), number of PMNs $\left(\mathrm{CD}_{4} 5^{+}, \mathrm{CD} 11 \mathrm{~b}^{+}, \mathrm{F} 4 / 80^{-}\right.$, and $\left.\mathrm{Ly}_{6 \mathrm{G}}{ }^{+}\right)$, and number of macrophages $\left(\mathrm{CD}_{4} 5^{+}, \mathrm{CD} 11 \mathrm{~b}^{+}\right.$, and $\left.\mathrm{F} 4 / 80^{+}\right)$. Although there was no significant difference in the total number of leukocytes or PMNs within the wounds, we did see a significant increase in the number of macrophages within the wounds of lipin$1^{\mathrm{m}} \mathrm{KO}$ mice (Figures 7A-C). These observations support our pathological scoring which showed no difference in immune infiltrate. We next examined the surface expression of CD206 (Mannose receptor) on macrophages in the wounds to determine if loss of lipin-1 altered macrophage polarization. We chose
CD206 as it is well accepted as a marker for M2 polarization in vivo and we had in vitro data demonstrating a significant reduction in MannR gene expression in lipin- $1^{\mathrm{m}} \mathrm{KO}$ BMDMs (34). Macrophages from wounds of lipin- $1{ }^{\mathrm{m}} \mathrm{KO}$ mice had a significant reduction in surface expression of CD206 compared to WT mice (Figure 7D). These data suggest the importance of lipin-1 in macrophages during wound healing.

\section{DISCUSSION}

Using our lipin- $1^{\mathrm{m}} \mathrm{KO}$ and lipin- $1^{\mathrm{mEnzy}} \mathrm{KO}$ mice, we demonstrated that lipin-1 enzymatic activity is dispensable for wound healing macrophage polarization and provided evidence suggesting that lipin-1 transcriptional co regulator function is required. Only macrophages lacking the entire lipin-1 protein failed to fully express canonical wound healing associated genes in response to IL-4 (5). Furthermore, impaired healing of full excision wound was also observed in lipin- $1^{\mathrm{m}} \mathrm{KO}$ mice but not lipin- $1^{\mathrm{mEnzy}} \mathrm{KO}$ mice. There was no alteration in systemic myeloid immune composition of lipin- $1^{\mathrm{m}} \mathrm{KO}$ mice after wounding, we did observe increased macrophage content and these macrophages had a reduction in the wound healing associated marker CD206. Combined, these data suggest to us that lipin-1 transcriptional co-regulator activity contributes to macrophage wound healing function that promotes wound closure. 


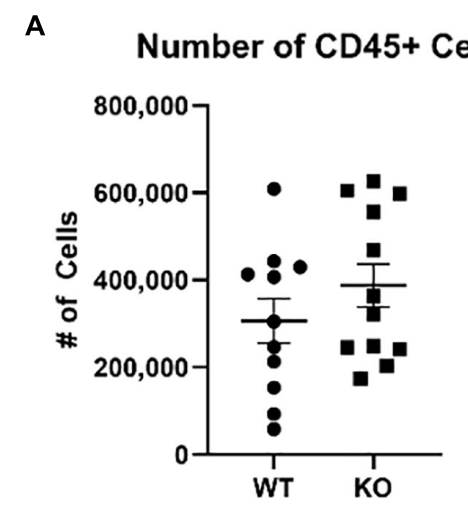

D

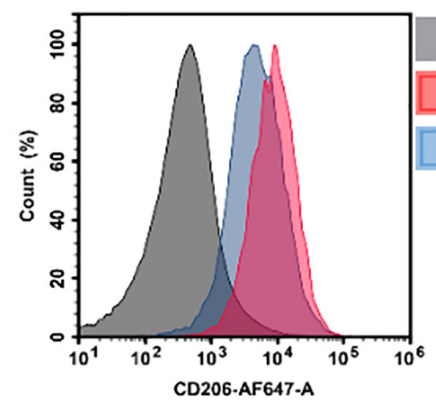

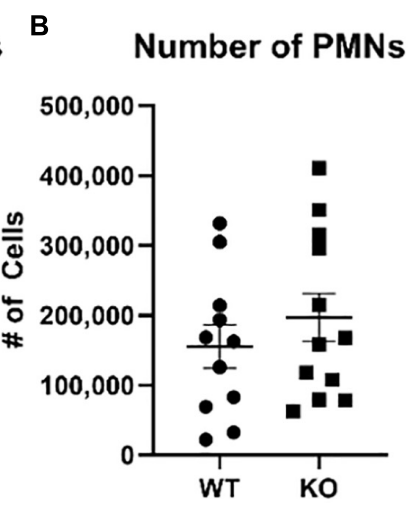

C
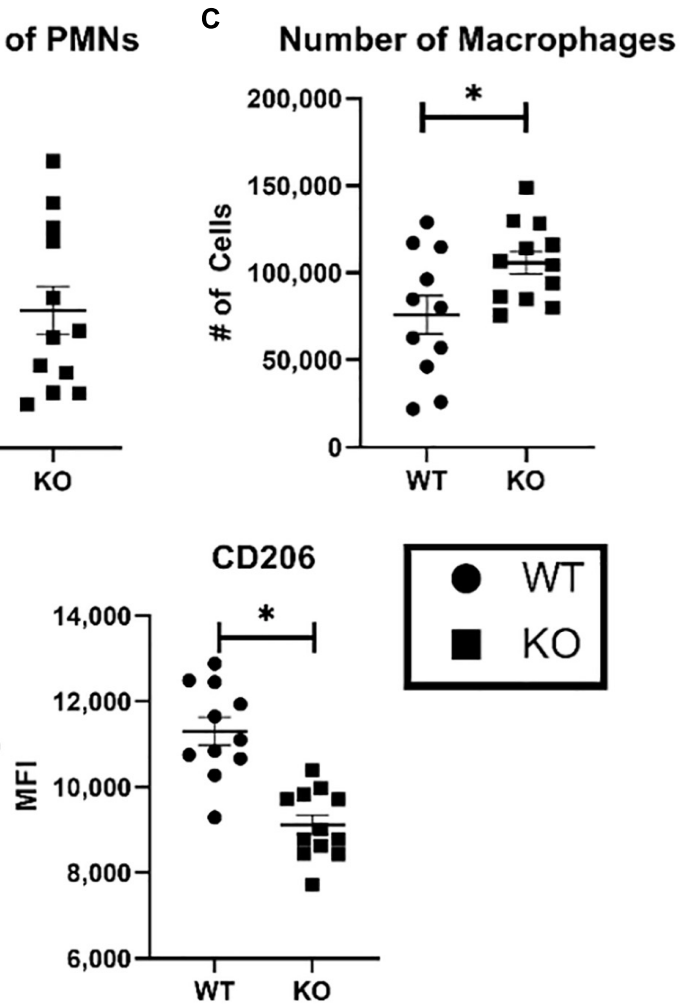

Unstained
Wildtype
Lipin- $1^{\mathrm{m}} \mathrm{KO}$

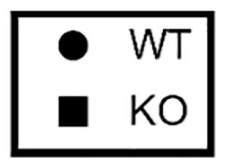

FIGURE 7 | Loss of full lipin-1 leads to reduce CD206 surface expression on macrophages within the wound. Cells were isolated from wounded tissue. Cells were stained with a panel of antibodies to identify (A) leukocytes, (B) neutrophils, and (C) macrophages. We also used an anti-CD206 antibody to characterize macrophage polarization within the wound. (D) A representative staining of macrophages from the wound and quantification of mice. Each dot represents an individual wound from 6 animals per group. The experiment was performed twice $(n=12)$ (mean \pm SEM). Data was tested for normalcy and $T$ test was used for analysis.

Lipin-1 is a multi-functional protein having both enzymatic and transcriptional coregulator function. The removal of exons 3 and 4 of lipin- 1 in our lipin- $1^{\mathrm{mEnzy}} \mathrm{KO}$ mice results in truncated lipin-1 that lacks enzymatic activity but retains the ability of lipin-1 to bind to transcription factors such as PPAR $\alpha$ and PPAR $\gamma$ (21). Removal of exon 7 from lipin-1 in our lipin$1^{\mathrm{m}} \mathrm{KO}$ mice causes a missense protein leading to loss of lipin-1 (and both activities) (22). BMDMs from the lipin- $1^{\mathrm{mEnzy}} \mathrm{KO}$ mice had equivalent expression of IL-4 elicited genes as WT BMDMs suggesting that lipin-1 enzymatic activity is dispensable for IL-4 mediated gene expression. Lipin- $1^{\mathrm{m}} \mathrm{KO}$ BMDMs had reduced expression of IL-4 mediated wound healing genes. IL4 binding to the IL- $4 \mathrm{R}$ leads to phosphorylation and activation of STAT6 leading to macrophage wound healing polarization. STAT6 binds to DNA promoters that leads to recruitment of PPAR $\gamma: R X R$ transcription factors to promote gene expression in macrophages $(2,29)$. In adipocytes and hepatocytes, lipin-1 binds to and augments the activity of both PPAR $\alpha$ and PPAR $\gamma$. In addition to augmentation of PPAR $\alpha$ and PPAR $\gamma$ activity, lipin-1 inhibits SREBP and NFAT by displacing them from their native promoters $(16,17)$. We propose lipin- 1 transcriptional coregulator activity promotes macrophages to a wound healing state during IL-4 stimulation. In support of this, macrophages lacking PPAR $\gamma$ fail to polarize to a wound healing phenotype, similar to the phenotype we observed in macrophage lacking full lipin1 (35). SREBP activity promotes the activation of the NLRP3 inflammasome leading to pro-inflammatory responses (20). While not typically active in macrophages, continued stimulation of macrophages lead to NFAT activity and promotion of proinflammatory responses such as IL- 6 and TNF- $\alpha$ (19). IL-6 and TNF- $\alpha$ are known to inhibit wound healing polarization. Thus, lipin-1 may also be repressing the activity of NFAT and SREBP allowing wound healing polarization. Our results and these published observations suggest to us that lipin-1 transcriptional coregulator activity promotes wound healing polarization.

Macrophage polarization is critical for effective in vivo wound healing where the number and phenotype of the resident and recruited macrophages determine the extent and efficiency of healing (36). Up to 1 day after wounding, pro-inflammatory macrophages initiate an acute inflammatory response; after that time frame, wound healing macrophages promote angiogenesis and tissue formation (37). The loss of enzymatic activity of lipin-1 reduces pro-inflammatory macrophage polarization $(7,9)$. We observed no defect in wound closure in lipin$1^{\text {mEnzy }} \mathrm{KO}$ mice compared to litter mate controls demonstrating that lipin-1 enzymatic activity is dispensable for myeloidmediated wound closure. In contrast, mice lacking both lipin1 activities had a defect in wound closure. We propose that 
the lipin-1 transcriptional co-regulatory activity in myeloid cells is responsible for aiding in wound closure during a full excisional wound. Mice lacking PPAR $\gamma$ from myeloid cells (LysMCre model) exhibit a significant delay in wound healing due to compromised granulation, collagen deposition, angiogenesis and a failure in clearance of apoptotic cells (5). PPAR $\gamma$ activation also promotes macrophage associated CD206 expression during a mouse model of liver wounding (38), providing evidence that PPAR activity promotes CD206 expression on macrophages during wounding. We see a significant reduction in CD206 gene expression in lipin- ${ }^{\mathrm{m}} \mathrm{KO}$ BMDMs and surface expression on macrophages isolated from the wounds of lipin- $1^{\mathrm{m}} \mathrm{KO}$ mice. Myeloid associated SREBP activity also contributes to wound closure, as mice with loss of SREBP activity in myeloid cells (LysMCre model) had enhanced wound closure (18). Lipin-1 can inhibit the activity of SREBP (17). Taking together we propose that the lipin-1 transcriptional co-regulatory activity in myeloid cells promotes beneficial wound closure responses.

We propose that the loss of wound healing observed in our lipin- $1^{\mathrm{m}} \mathrm{KO}$ mice is due to loss of transcriptional co-regulator activity from monocytes and macrophages. However, LysM-Cre was used to knockout lipin-1 in our mice, and LysM expression is not restricted to monocytes and macrophages. Analysis of $L y s M$ Cre-mediated gene deletion demonstrates gene excision in dendritic cells (DC) and neutrophils, as well as monocytes and macrophages $(26,39)$. We suggest that loss of lipin-1 in DC is not responsible for the difference in wound closure in our lipin$1^{\mathrm{m}} \mathrm{KO}$ mice. DCs enhance $\mathrm{T}$ cell/B cell responses, rather than innate immune responses, and our difference in wound closure is more prevalent in earlier phase of healing (likely prior to $\mathrm{T}$ cell responses). The contribution of lipin-1 to DC function is completely unknown and needs to be looked at in the future. Neutrophils clearly contribute to wound healing and we observe PMNs within the wounds of both WT and Lipin- ${ }^{\mathrm{m}} \mathrm{KO}$ mice (40). Lipin-1 is not readily detected in neutrophils, however, if inflammation drive increases in lipin-1 expression in neutrophils is unknown. Future work will need to address the possibility of neutrophil-associated lipin-1 contribution to wound closure (7). We propose though, that the most likely effect of myeloid loss of lipin-1 is on macrophage function. We observe reduction in wound healing associated gene in lipin- $1^{\mathrm{m}} \mathrm{KO}$ BMDMS that are known to contribute to wound closure, and a reduction in CD206 surface expression on macrophages within the wounds of lipin- ${ }^{\mathrm{m}} \mathrm{KO}$ mice. Thus, though possible loss of lipin-1 in other cells beside macrophages may contribute to reduction in wound closure, at the very least the loss of lipin-1 in macrophages is also a contributing factor.

Our data highlight the role of lipin-1 transcriptional coregulator activity within macrophage function, specifically for wound healing polarization. Furthermore, we provide evidence that the lack of myeloid-associated lipin-1 transcriptional co-regulator activity has in vivo consequences. Macrophage responses are now recognized to play crucial roles in a diverse array of pathologies like atherosclerosis, arthritis, osteoporosis, and sterile inflammation. Beyond sterile inflammation, IL-4 mediated macrophage responses are critical to control and clearance of numerous parasitic infections as well (41). Thus, the contribution of lipn-1 to myeloid cells function is likely to be important beyond sterile inflammation. Future work will be needed to better understand the mechanisms by which lipin-1 transcriptional co-regulator activity drives macrophage function in different pathological conditions of sterile inflammation and parasitic infections.

\section{DATA AVAILABILITY STATEMENT}

The raw data supporting the conclusions of this article will be made available by the authors, without undue reservation, to any qualified researcher.

\section{ETHICS STATEMENT}

All animal studies were approved by the LSU Health Sciences Center-Shreveport Institutional Animal Care and Use Committee.

\section{AUTHOR CONTRIBUTIONS}

SC performed the experimental work, data analysis, and wrote the manuscript. RMS, CB, AY, RM, and RSS assisted with experimental design, experimental work, and data analysis. BF provided critical reagents necessary to complete and finalize experiments as well as intellectual input on the manuscript writing. MW conceived the idea, designed the study, obtained the funding, analyzed and interpreted the data, and wrote and revised the manuscript. All authors were involved in the final approval of the manuscript.

\section{FUNDING}

This work was supported by the National Heart, Lung, and Blood Institute R01 HL131844 (MW) and R01 HL119225 (BF). Malcolm Feist Predoctoral Fellowship (CB). The content is solely the responsibility of the authors and does not necessarily represent the official views of the National Institutes of Health.

\section{ACKNOWLEDGMENTS}

We would like to thank David Custis for his help with running samples related to flow cytometric experiments, Deshawn Blankenship for sectioning all tissues used in this study, and Gabrielle Gahn for determining genotypes of all mice. This manuscript has been released as a preprint at BioRxiv (42).

\section{SUPPLEMENTARY MATERIAL}

The Supplementary Material for this article can be found online at: https://www.frontiersin.org/articles/10.3389/fimmu. 2020.00787/full\#supplementary-material 


\section{REFERENCES}

1. Orecchioni M, Ghosheh Y, Akula Bala P, Ley K. Macrophage polarization: different gene signatures in M1 (LPS+) vs. classically and M2 (LPS-) vs. Alternatively activated macrophages. Front Immunol. (2019) 10: 1084. doi: 10.3389/fimmu.2019.01084

2. Szanto A, Balint BL, Nagy ZS, Barta E, Dezso B, Pap A, et al. STAT6 transcription factor is a facilitator of the nuclear receptor PPARgammaregulated gene expression in macrophages and dendritic cells. Immunity. (2010) 33:699-712. doi: 10.1016/j.immuni.2010.11.009

3. Glass CK, Saijo K. Nuclear receptor transrepression pathways that regulate inflammation in macrophages and T cells. Nat Rev Immunol. (2010) 10: 365-76. doi: 10.1038/nri2748

4. Jennewein C, Kuhn AM, Schmidt MV, Meilladec-Jullig V, von Knethen A, Gonzalez FJ, et al. Sumoylation of peroxisome proliferator-activated receptor gamma by apoptotic cells prevents lipopolysaccharide-induced NCoR removal from kappaB binding sites mediating transrepression of proinflammatory cytokines. J Immunol. (2008) 181:5646-52. doi: 10.4049/jimmunol.181. 8.5646

5. Chen H, Shi R, Luo B, Yang X, Qiu L, Xiong J, et al. Macrophage peroxisome proliferator-activated receptor gamma deficiency delays skin wound healing through impairing apoptotic cell clearance in mice. Cell Death Dis. (2015) 6:e1597. doi: 10.1038/cddis.2014.544

6. Csaki LS, Reue K. Lipins: multifunctional lipid metabolism proteins. Annu Rev Nutr. (2010) 30:257-72. doi: 10.1146/annurev.nutr.012809.104729

7. Meana C, Pena L, Lorden G, Esquinas E, Guijas C, Valdearcos M, et al. Lipin-1 integrates lipid synthesis with proinflammatory responses during TLR activation in macrophages. J Immunol. (2014) 193: 4614-22. doi: 10.4049/ jimmunol.1400238

8. Navratil AR, Vozenilek AE, Cardelli JA, Green JM, Thomas MJ, Sorci-Thomas MG, et al. Lipin-1 contributes to modified low-density lipoprotein-elicited macrophage pro-inflammatory responses. Atherosclerosis. (2015) 242: 424-32. doi: 10.1016/j.atherosclerosis.2015.08.012

9. Vozenilek AE, Navratil AR, Green JM, Coleman DT, Blackburn CMR, Finney AC, et al. Macrophage-associated lipin-1 enzymatic activity contributes to modified low-density lipoprotein-induced proinflammatory signaling and atherosclerosis. Arterioscler Thromb Vasc Biol. (2018) 38: 324-34. doi: 10.1161/ ATVBAHA.117.310455

10. Balboa MA, de Pablo N, Meana C, Balsinde J. The role of lipins in innate immunity and inflammation. Biochim Biophys Acta Mol Cell Biol Lipids. (2019) 1864:1328-37. doi: 10.1016/j.bbalip.2019.06.003

11. Bi L, Jiang Z, Zhou J. The role of lipin-1 in the pathogenesis of alcoholic fatty liver. Alcohol Alcohol. (2015) 50:146-51. doi: 10.1093/alcalc/agu102

12. Chen Z, Gropler MC, Mitra MS, Finck BN. Complex interplay between the lipin 1 and the hepatocyte nuclear factor 4 alpha (HNF4alpha) pathways to regulate liver lipid metabolism. PLoS One. (2012) 7: e51320. doi: 10.1371/ journal.pone.0051320

13. Chen Z, Gropler MC, Norris J, Lawrence JC Jr., Harris TE, Finck BN. Alterations in hepatic metabolism in fld mice reveal a role for lipin 1 in regulating VLDL-triacylglyceride secretion. Arterioscler Thromb Vasc Biol. (2008) 28:1738-44. doi: 10.1161/ATVBAHA.108.171538

14. Finck BN, Gropler MC, Chen Z, Leone TC, Croce MA, Harris TE, et al. Lipin 1 is an inducible amplifier of the hepatic PGC-1alpha/PPARalpha regulatory pathway. Cell Metab. (2006) 4:199-210. doi: 10.1016/j.cmet.2006. 08.005

15. Phan J, Peterfy M, Reue K. Lipin expression preceding peroxisome proliferator-activated receptor-gamma is critical for adipogenesis in vivo and in vitro. J Biol Chem. (2004) 279:29558-64. doi: 10.1074/jbc.M4035 06200

16. Kim HB, Kumar A, Wang L, Liu GH, Keller SR, Lawrence JC Jr., et al. Lipin 1 represses NFATc4 transcriptional activity in adipocytes to inhibit secretion of inflammatory factors. Mol Cell Biol. (2010) 30: 3126-39. doi: 10.1128/MCB. 01671-09

17. Peterson TR, Sengupta SS, Harris TE, Carmack AE, Kang SA, Balderas E, et al. mTOR complex 1 regulates lipin 1 localization to control the SREBP pathway. Cell. (2011) 146:408-20. doi: 10.1016/j.cell.2011.06.034

18. Kusnadi A, Park SH, Yuan R, Pannellini T, Giannopoulou E, Oliver D, et al. The cytokine TNF promotes transcription factor SREBP activity and binding to inflammatory genes to activate macrophages and limit tissue repair. Immunity. (2019) 51:241-257e9. doi: 10.1016/j.immuni.2019. 06.005

19. Minematsu H, Shin MJ, Celil Aydemir AB, Kim KO, Nizami SA, Chung GJ, et al. Nuclear presence of nuclear factor of activated T cells (NFAT) c3 and c4 is required for Toll-like receptor-activated innate inflammatory response of monocytes/macrophages. Cell Signal. (2011) 23:1785-93. doi: 10.1016/j.cellsig. 2011.06.013

20. Varghese JF, Patel R, Yadav UCS. Sterol regulatory element binding protein (SREBP) -1 mediates oxidized low-density lipoprotein (oxLDL) induced macrophage foam cell formation through NLRP3 inflammasome activation. Cell Signal. (2019) 53:316-26. doi: 10.1016/j.cellsig.2018.10.020

21. Mitra MS, Chen Z, Ren H, Harris TE, Chambers KT, Hall AM, et al. Mice with an adipocyte-specific lipin 1 separation-of-function allele reveal unexpected roles for phosphatidic acid in metabolic regulation. Proc Natl Acad Sci USA. (2013) 110:642-7. doi: 10.1073/pnas.1213493110

22. Schweitzer GG, Collier SL, Chen Z, McCommis KS, Pittman SK, Yoshino J, et al. Loss of lipin 1-mediated phosphatidic acid phosphohydrolase activity in muscle leads to skeletal myopathy in mice. FASEB J. (2019) 33:652-67. doi: 10.1096/fj.201800361R

23. Moreira CF, Cassini-Vieira P, da Silva MF, Barcelos LS. Skin wound healing model - excisional wounding and assessment of lesion area. Bio Protocol. (2015) 5:e1661. doi: 10.21769/BioProtoc.1661

24. Woolard MD, Barrigan LM, Fuller JR, Buntzman AS, Bryan J, Manoil C, et al. Identification of Francisella novicida mutants that fail to induce prostaglandin E(2) synthesis by infected macrophages. Front Microbiol. (2013) 4:16. doi: $10.3389 /$ fmicb. 2013.00016

25. Li Z, Gothard E, Coles MC, Ambler CA. Quantitative methods for measuring repair rates and innate-immune cell responses in wounded mouse skin. Front Immunol. (2018) 9:347. doi: 10.3389/fimmu.2018.00347

26. Clausen BE, Burkhardt C, Reith W, Renkawitz R, Forster I. Conditional gene targeting in macrophages and granulocytes using LysMcre mice. Transgenic Res. (1999) 8:265-77. doi: 10.1023/A:1008942828960

27. Martinez FO, Helming L, Gordon S. Alternative activation of macrophages: an immunologic functional perspective. Annu Rev Immunol. (2009) 27:451-83. doi: 10.1146/annurev.immunol.021908.132532

28. Varshney P, Yadav V, Saini N. Lipid rafts in immune signalling: current progress and future perspective. Immunology. (2016) 149:13-24. doi: 10.1111/ imm. 12617

29. Pesu M, Takaluoma K, Aittomäki S, Lagerstedt A, Saksela K, Kovanen PE, et al. Interleukin-4-induced transcriptional activation by stat6 involves multiple serine/threonine kinase pathways and serine phosphorylation of stat6. Blood. (2000) 95:494-502. doi: 10.1182/blood.V95.2.494

30. Rubio JM, Rodriguez JP, Gil-de-Gomez L, Guijas C, Balboa MA, Balsinde J. Group V secreted phospholipase A2 is upregulated by IL-4 in human macrophages and mediates phagocytosis via hydrolysis of ethanolamine phospholipids. J Immunol. (2015) 194:3327-39. doi: 10.4049/jimmunol. 1401026

31. Knipper JA, Willenborg S, Brinckmann J, Bloch W, Maaß T, Wagener R, et al. Interleukin- 4 receptor $\alpha$ signaling in myeloid cells controls collagen fibril assembly in skin repair. Immunity. (2015) 43:803-16. doi: 10.1016/j.immuni. 2015.09.005

32. Krzyszczyk P, Schloss R, Palmer A, Berthiaume F. The role of macrophages in acute and chronic wound healing and interventions to promote prowound healing phenotypes. Front Physiol. (2018) 9:419. doi: 10.3389/fphys. 2018.00419

33. Olingy CE, San Emeterio CL, Ogle ME, Krieger JR, Bruce AC, Pfau DD, et al. Non-classical monocytes are biased progenitors of wound healing macrophages during soft tissue injury. Sci Rep. (2017) 7:447. doi: 10.1038/ s41598-017-00477-1

34. Stein M, Keshav S, Harris N, Gordon S. Interleukin 4 potently enhances murine macrophage mannose receptor activity: a marker of alternative immunologic macrophage activation. J Exp Med. (1992) 176:287-92. doi: 10. 1084/jem.176.1.287

35. Odegaard JI, Ricardo-Gonzalez RR, Goforth MH, Morel CR, Subramanian V, Mukundan L, et al. Macrophage-specific PPARgamma controls alternative activation and improves insulin resistance. Nature. (2007) 447: 1116-20. doi: 10.1038 /nature 05894 
36. Koo J, Jang H, Lee Y, Moon YJ, Bae EJ, Yun SK, et al. Myeloid cell-specific sirtuin 6 deficiency delays wound healing in mice by modulating inflammation and macrophage phenotypes. Exp Mol Med. (2019) 51:1-10. doi: 10.1038/ s12276-019-0248-9

37. Lucas T, Waisman A, Ranjan R, Roes J, Krieg T, Muller W, et al. Differential roles of macrophages in diverse phases of skin repair. J Immunol. (2010) 184:3964-77. doi: 10.4049/jimmunol.0903356

38. Linares I, Farrokhi K, Echeverri J, Kaths JM, Kollmann D, Hamar M, et al. PPAR-gamma activation is associated with reduced liver ischemia-reperfusion injury and altered tissue-resident macrophages polarization in a mouse model. PLoS One. (2018) 13:e0195212. doi: 10.1371/journal.pone.0195212

39. Abram CL, Roberge GL, Hu Y, Lowell CA. Comparative analysis of the efficiency and specificity of myeloid-Cre deleting strains using ROSA-EYFP reporter mice. J Immunol Methods. (2014) 408: 89-100. doi: 10.1016/j.jim. 2014.05.009

40. de Oliveira S, Rosowski EE, Huttenlocher A. Neutrophil migration in infection and wound repair: going forward in reverse. Nat Rev Immunol. (2016) 16:37891. doi: 10.1038/nri.2016.49
41. Rolot M, Dewals BG. Macrophage activation and functions during helminth infection: recent advances from the laboratory mouse. J Immunol Res. (2018) 2018:2790627. doi: 10.1155/2018/2790627

42. Chandran S, Schilke RM, Blackburn CMR, Yurochko A, Mirza R, Scott RS, et al. Lipin-1 contributes to IL-4 mediated macrophage polarization. bioRxiv. (2019). [Preprint]. doi: 10.1101/2019.12.23.887109

Conflict of Interest: The authors declare that the research was conducted in the absence of any commercial or financial relationships that could be construed as a potential conflict of interest.

Copyright (c) 2020 Chandran, Schilke, Blackburn, Yurochko, Mirza, Scott, Finck and Woolard. This is an open-access article distributed under the terms of the Creative Commons Attribution License (CC BY). The use, distribution or reproduction in other forums is permitted, provided the original author(s) and the copyright owner(s) are credited and that the original publication in this journal is cited, in accordance with accepted academic practice. No use, distribution or reproduction is permitted which does not comply with these terms. 